\title{
Fertility preservation techniques: laboratory and clinical progress and current issues
}

\author{
R A Anderson \\ Centre for Reproductive Biology, The Queen's Medical Research Institute, University of Edinburgh, 47 Little France \\ Crescent, Edinburgh EH16 4TJ, UK \\ Correspondence should be addressed to R A Anderson; Email: richard.anderson@ed.ac.uk
}

\begin{abstract}
Human fertility is dependent on maturation of germ cells through meiosis and their association with supporting cells, which in the female are also the source of sex steroids. These processes are sensitive to both chemotherapy and radiotherapy thus can be damaged by anti-cancer treatments. The uterus is also sensitive to radiotherapy. Our understanding of and the ability to manipulate fertility has increased together with survival rates from many cancers, particularly those affecting children, younger men, and women. The growth of interest in fertility preservation for cancer patients is a natural union of these two fields. Sperm banking has been available for many years, and is a recognized and evidencebased option for men that should be available to all. Options for women and pre-pubertal boys and girls are, however, more experimental, other than for women of committing oocytes to fertilization and cryopreservation as embryos. This Focus Issue of Reproduction aims to address the current status of some of the clinical and laboratory aspects of this burgeoning subspecialty to highlight not only areas of progress but also areas of uncertainty where future developments are required to allow the provision of accurate information, and safe and effective treatments.

Reproduction (2008) 136 667-669
\end{abstract}

Fertility preservation is a rapidly expanding area both in the laboratory and in clinical practice. Much of this emerging interest reflects the greatly improved survival rates of young men and women with malignant disease, and indeed this has been one of the major success stories of medicine over the last couple of decades. Increasingly, the emphasis is on improved quality as well as quantity of survival and naturally for many the prospect of losing one's fertility is of major importance. In both the United States and United Kingdom working parties organized by relevant professional organizations have recently produced comprehensive reports discussing the impact of cancer therapies on reproductive function and the current status of produce to the management of this problem (Lee et al. 2006, Report of a Working Party of the Royal College of Physicians, Royal College of Radiologists and Royal College of Obstetricians and Gynecologists 2007). In this issue of Reproduction, we bring together a series of articles to consider the state of the art of fertility preservation and highlight some of the outstanding clinical and laboratory aspects of this field, particularly areas of clinical uncertainty and where basic science developments are required before treatments that are theoretically very promising can be introduced into practice.

The explosion of interest can be dated back to the demonstration by Roger Gosden, David Baird and colleagues that ovarian function and fertility could be restored in sheep following removal and cryopreservation of ovarian tissue with subsequent replacement into the pelvis (Gosden et al. 1994), albeit at the cost of the loss of most of the follicles in the cryopreserved tissue (Baird et al. 1999). Fittingly, Gosden provides in this issue a scholarly account of the early and more recent history of ovarian transplantation (Gosden 2008). This has now been used successfully with a small number of babies born to women who have had ovarian tissue cryopreserved and later replaced. While these successes are enormously encouraging for patients and their physicians there remain considerable uncertainties regarding all aspects of this approach to fertility preservation, including selection of appropriate patients and the most appropriate surgical approaches in this situation. These and related clinical issues are reviewed (Anderson et al. 2008). A central problem is the paucity of accurate information as to the degree of gonadotoxicity of chemotherapy regimens that develop and change rapidly. Our ability to assess the effects on gonadal function has been greatly enhanced by the development of new markers of the number of small follicles in women (i.e., anti Müllerian hormone; Anderson et al. 2006) and endocrine markers of spermatogenesis in men (i.e., inhibin B; van Beek et al. 2007). It is hoped that the 
demonstration that ovarian tissue cryopreservation can be successful and of increased success rates with oocyte cryopreservation/vitrification (Gook \& Edgar 2007) will encourage the collaborations needed between oncologists and reproductive specialists to investigate and develop these techniques further. Particularly pertinent is the application of this approach to children, and the need to consider the ethical aspects of children undergoing procedures that remain experimental and of uncertain benefit at the time of high emotional tension and vulnerability for them and their parents. It is well recognized that few men return to use cryopreserved sperm, although the reasons for this (e.g., how many retain their fertility) is less clear. The same may prove true for women and this is more important when gamete storage has required invasive surgery or drug treatment, and may have delayed anti-cancer treatments.

Complimenting these clinical issues is a comprehensive review of the current status of in vitro follicular maturation (Picton et al. 2008). This article gives a full analysis of progress and problems in the development of multi-stage techniques to support follicular growth from the primordial stage through the antral stages and subsequent in vitro maturation of oocytes. Mice have been successfully born using fetal ovary as a starting point and there are clear advances in early human follicle culture (Telfer et al. 2008), but Picton et al. highlight the many issues that remain before this can be used safely and effectively in clinical practice, including the major concerns regarding epigenetic modifications of the oocyte genome which may occur in culture.

Prevention is always better than cure, and Meistrich \& Shetty review the issue of gonadal protection from chemotherapy and radiotherapy (Meistrich \& Shetty 2008). While the rodent studies have led to valuable insights into the developmental regulation of testicular stem cells, the application of this to patients is unclear. However, the well-recognized observation that occasionally men can show very late restoration of spermatogenesis many years after chemotherapy suggests that when some spermatogonia survive they can later repopulate the seminiferous epithelium, and better understanding of the regulation of this process may be of considerable benefit to many men. The concept of gonadal protection remains very attractive with many patients (especially women) already treated with GNRH analogues prior to chemotherapy despite an absence of good evidence that this is of benefit (Blumenfeld 2007). High quality randomized studies are currently underway and it is hoped that they will provide clear data that will be of immediate clinical relevance.

While sperm storage is an established option for men and post-pubertal boys, options for pre-pubertal boys remain experimental. Considerable progress has been made, however, in establishing methods for somatic gonadal stem cell recovery from tissue for storage and possible re-implantation, and storage of testicular tissue for subsequent culture and in vitro spermatogenesis, as reviewed by Ehmcke \& Schlatt (2008). Such studies will also contribute to our basic understanding of the biology of the male gamete, and disorders of spermatogenesis.

There are many other exciting developments in reproductive biology at present of relevance to fertility preservation that are not covered in this Issue as they are at the early stages of understanding. These include the possibility of developing functional gametes from embryonic stem cells (Hubner et al. 2003, Nayernia et al. 2006), and potentially in the future from induced pluripotent cells (Takahashi et al. 2007). The clinical use of artificial gametes is some way off and is likely to involve considerable public debate and legislative activity, but with an increasing number of the young men and women cured of their cancer but sterilized by the treatment, it is important that this approach is given full consideration. The possibility that the ovary may have regenerative capacity has also attracted considerable debate in the last few years (Johnson et al. 2005, Telfer et al. 2005): at present many remain uncertain about this, although in this as yet embryonic era of regenerative medicine, knowledge derived from the regeneration of ageing heart, brain, and bones may be transferable to the reproductive system.

\section{Declaration of interest}

The author declares that there is no conflict of interest that could be perceived as prejudicing the impartiality of this editorial.

\section{Funding}

This manuscript did not receive any specific grant from any funding agency in the public, commercial or not-for-profit sector.

\section{References}

Anderson RA, Themmen APN, Al Qahtani A, Groome NP \& Cameron DA 2006 The effects of chemotherapy and long-term gonadotrophin suppression on the ovarian reserve in premenopausal women with breast cancer. Human Reproduction 21 2583-2592.

Anderson RA, Wallace WHB \& Baird DT 2008 Ovarian cryopreservation for fertility preservation: indications and outcomes. Reproduction 136 681-689.

Baird DT, Webb R, Campbell BK, Harkness LM \& Gosden RG 1999 Longterm ovarian function in sheep after ovariectomy and transplantation of autografts stored at $-196{ }^{\circ} \mathrm{C}$. Endocrinology $140462-471$.

van Beek RD, Smit M, van den Heuvel-Eibrink MM, de Jong FH, HakvoortCammel FG, van den Bos C, van den Berg H, Weber RF \& de Muinck Keizer-Schrama SM 2007 Inhibin B is superior to FSH as a serum marker for spermatogenesis in men treated for Hodgkin's lymphoma with chemotherapy during childhood. Human Reproduction 22 3215-3222.

Blumenfeld Z 2007 How to preserve fertility in young women exposed to chemotherapy? The role of GnRH agonist cotreatment in additon to cryopreservation of embrya, oocytes, or ovaries Oncologist 12 1044-1054.

Ehmcke J \& Schlatt S 2008 Animal models for fertility preservation in the male. Reproduction 136 717-723. 
Gook DA \& Edgar DH 2007 Human oocyte cryopreservation. Human Reproduction Update 13 591-605.

Gosden RG 2008 Ovary and uterus transplantation. Reproduction 136 671-680.

Gosden RG, Baird DT, Wade JC \& Webb R 1994 Restoration of fertility to oophorectomized sheep by ovarian autografts stored at $-196^{\circ} \mathrm{C}$. Human Reproduction 9 597-603.

Hubner K, Fuhrmann G, Christenson LK, Kehler J, Reinbold R, De La Fuente R, Wood J, Strauss JF III, Boiani M \& Scholer HR 2003 Derivation of oocytes from mouse embryonic stem cells. Science 300 1251-1256.

Johnson J, Bagley J, Skaznik-Wikiel M, Lee HJ, Adams GB, Niikura Y, Tschudy KS, Tilly JC, Cortes ML, Forkert R et al. 2005 Oocyte generation in adult mammalian ovaries by putative germ cells in bone marrow and peripheral blood. Cell 122 303-315.

Lee SJ, Schover LR, Partridge AH, Patrizio P, Wallace WH, Hagerty K, Beck LN, Brennan LV \& Oktay K 2006 American Society of Clinical Oncology recommendations on fertility preservation in cancer patients. Journal of Clinical Oncology 24 2917-2931.

Meistrich ML \& Shetty G 2008 Hormonal suppression for fertility preservation in males and females. Reproduction 136 691-701.
Nayernia K, Nolte J, Michelmann HW, Lee JH, Rathsack K, Drusenheimer N, Dev A, Wulf G, Ehrmann IE, Elliott DJ et al. 2006 In vitrodifferentiated embryonic stem cells give rise to male gametes that can generate offspring mice. Developmental Cell 11 125-132.

Picton HM, Harris SE, Maruvi W \& Chambers EL 2008 The in vitro growth and maturation of follicles. Reproduction 136 703-715.

Report of a Working Party of the Royal College of Physicians, Royal College of Radiologists and Royal College of Obstetricians and Gynaecologists 2007 The Effects of Cancer Treatment on Reproductive Functions: Guidance on Management. London: Royal College of Physicians.

Takahashi K, Tanabe K, Ohnuki M, Narita M, Ichisaka T, Tomoda K \& Yamanaka S 2007 Induction of pluripotent stem cells from adult human fibroblasts by defined factors. Cell 131 861-872.

Telfer EE, Gosden RG, Byskov AG, Spears N, Albertini D, Andersen CY, Anderson R, Braw-Tal R, Clarke H, Gougeon A et al. 2005 On regenerating the ovary and generating controversy. Cell 122 821-822.

Telfer EE, McLaughlin M, Ding C \& Thong KJ 2008 A two step serum free culture system supports development of human oocytes form primordial follicles in the presence of activin. Human Reproduction $\mathbf{2 3}$ 1151-1158. 